\title{
Hollow Silica Nanotubes for Space-Confined Synthesis of Noble Metal Nanorods and Nanopeapods
}

\author{
Meng Chen ${ }^{\ddagger a}$, Xianwei Xie ${ }^{\ddagger a}$, Yanan Wang ${ }^{a}$, Xinchang Pang, ${ }^{a *}$ and Zhongfan Jia ${ }^{\text {b* }}$
}

\begin{abstract}
a Henan Joint International Research Laboratory of Living Polymerizations and Functional Nanomaterials, Henan Key Laboratory of Advanced Nylon Materials and Application, School of Materials Science and Engineering, Zhengzhou University, Zhengzhou 450001, China.

Email: pangxinchang1980@163.com

b Institute for Nanoscale Science and Technology, College of Science and Engineering, Flinders University, Bedford Park, South Australia 5042, Australia.

Email: zhongfan.jia@flinders.edu.au

¥ These authors contributed equally.
\end{abstract}


Supporting Information

\section{Experimental section}

\section{Materials}

Cellulose powder (microcrystalline, MP Biomedicals LLC), allyl chloride (> 98.0\%, TCI) and 1methylimidazole (99\%, Alfa Aesar) were used as received. 3-(Trimethoxysilyl)-propyl methacrylate (TMSPMA monomer, 98\%), 2-bromoisobutyryl bromide (98\%), $N, N, N^{\prime}, N^{\prime \prime}, N^{\prime \prime}-$ pentamethyldiethylene triamine (PMDETA, 99\%), tris[2-(dimethylamino)ethyl]amine (Me ${ }_{6}$-TREN, 97\%), anhydrous benzene (99.8\%), and ammonium hydroxide solution (28\%) were purchased from Sigma-Aldrich and used as starting materials without further purification. $\mathrm{CuBr}$ (98\%, Sigma-Aldrich) and styrene (St., SigmaAldrich, $\geq 99 \%$ ) were purified according to literatures. $N, N$-dimethylformamide (DMF, Fisher Scientific, 99.9\%) was dried by $\mathrm{CaH}_{2}$ and distilled under reduced pressure prior to use. Gold(III) chloride trihydrate $\left(\mathrm{HAuCl}_{4} \cdot 3 \mathrm{H}_{2} \mathrm{O}, \geq 99.9 \%\right)$, silver nitrate $\left(\mathrm{AgNO}_{3}, \geq 98 \%\right)$, L-ascorbic acid ( $\left.\geq 98 \%\right)$, tertbutylamine borane (TBAB, 97\%), chloroplatinic acid hexahydrate $\left(\mathrm{H}_{2} \mathrm{PtCl}_{6} .6 \mathrm{H}_{2} \mathrm{O}, \mathrm{ACS}\right.$ reagent, $\geq 37.50 \%$ Pt basis), and ethylene glycol (EG, anhydrous, 99.8\% ) were purchased from Sigma-Aldrich and used as starting materials without further purification. Thiol-terminated poly(ethylene glycol) methyl ether (mPEG-SH, $M_{n}=5,000$; Polymer Source), amino-terminated poly(ethylene glycol) methyl ether (mPEG$\mathrm{NH}_{2}, M_{n}=5,000$ ), thiol-terminated polystyrene (PS-SH, $M_{n}=2,000$ ) and amino-terminated polystyrene (PS-NH $\mathrm{NH}_{2}, M_{n}=2,000$ ) were purchased from Polymer Source and used as received. All other reagents were purified by common purification procedures.

\section{Synthesis of linear cellulose-based macroinitiator (i.e., cellulose-Br) by a two-step esterification process}

Firstly, the ionic liquid (1-allyl-3-methylimidazolium chloride, AMIMCI) was prepared according to the literature. In a typical process, $50 \mathrm{~mL}$ of 1-methylimidazole and $100 \mathrm{~mL}$ of allyl chloride were added to a $250 \mathrm{~mL}$ round-bottomed flask. Then the reaction system was refluxed under stirring at $55^{\circ} \mathrm{C}(8 \mathrm{~h}) \cdot \underline{33}$ The excess chemical reagents were removed by vacuum distillation, and the resulting viscous and slightly yellowish product (AMIMCI) is obtained.

Linear cellulose- $\mathrm{Br}$ macroinitiator was synthesized according to the reported procedure shown in Figure 1. Prior to dispersing in $60 \mathrm{~mL}$ of ionic liquid, cellulose $(6.0 \mathrm{~g})$ was dried in a vacuum oven at $80^{\circ} \mathrm{C}$ for $24 \mathrm{~h}$, and then a trace amount of water was removed by the azeotropic distillation with anhydrous toluene $(60 \mathrm{~mL})$. The reaction mixture was heated to $80^{\circ} \mathrm{C}$ under stirring until the cellulose was completely dissolved in ionic liquid to form a viscous and transparent solution. $50 \mathrm{~mL}$ of anhydrous NMP and $50 \mathrm{~mL}$ of anhydrous DMF were added to the mixture. 2-Bromoisobutyryl bromide $(28 \mathrm{~mL}$, 2eq to the hydroxyl groups) was added dropwise to the cellulose solution under vigorous stirring at 0 


\section{Supporting Information}

${ }^{\circ} \mathrm{C}$. The reaction temperature was maintained at $0{ }^{\circ} \mathrm{C}$ for $1 \mathrm{~h}$ and then slowly increased to room temperature, at which the esterification reaction was allowed to continue for $24 \mathrm{~h}$. The resulting brownish solution was added to $500 \mathrm{~mL}$ DI water, yielding white precipitate. After filtration, the final product was purified by dissolution-precipitation twice with acetone and DI water and dried at $60^{\circ} \mathrm{C}$ in a vacuum for one day.

In order to maximize the conversion of hydroxyl groups to $\mathrm{Br}$ functionalities, the second esterification process was performed. First, $10 \mathrm{~g}$ of purified cellulose- $\mathrm{Br}$ was dissolved in $50 \mathrm{~mL}$ of anhydrous NMP and kept in an ice-water bath. $10 \mathrm{~mL}$ of 2-bromoisobutyryl bromide was then added dropwise into the reaction solution. The reaction system was first maintained in an ice water bath for $2 \mathrm{~h}$, and then slowly increased to room temperature. The reaction solution was kept at room temperature for $24 \mathrm{~h}$. The resulting crude solution was poured into $200 \mathrm{~mL}$ of DI water, yielding white precipitate. After filtration, the final product was purified by dissolution-precipitation twice with acetone and DI water and dried at $60^{\circ} \mathrm{C}$ in a vacuum for one day.

The crude cellulose- $\mathrm{Br}$ was separated into a series of pure linear macroinitiators with very low PDI $(<1.2)$ by fractional precipitation technique with acetone as the solvent and DI water as precipitator. Three samples with different molecular weights were thus obtained. The chemical compositions of cellulose-Br were confirmed by ${ }^{1} \mathrm{H}-\mathrm{NMR}$ in DMSO- $d_{6}$ : $\delta=1.6$ (broad $s, \mathrm{CH}_{3}$ ), 3.4-5.8 (protons of cellulose backbone); FTIR: $2935 \mathrm{~cm}^{-1}\left(\mathrm{v}_{\mathrm{C}-\mathrm{H}}\right), 1734 \mathrm{~cm}^{-1}\left(\mathrm{v}_{\mathrm{C}=0}\right), 1161 \mathrm{~cm}^{-1}\left(\mathrm{v}_{\mathrm{C}-\mathrm{O}-\mathrm{C}}\right), 1036$ and $1109 \mathrm{~cm}^{-1}$ (coupled $\mathrm{v}_{\mathrm{C}-\mathrm{C}}$ and $\left.v_{C-O}\right)$.

\section{Synthesis of bottlebrush-like cellulose- $g$-polystyrene (cellulose- $g$-PS) by ATRP utilizing cellulose-Br as a macroinitiator}

Bottlebrush-like cellulose- $g$-polystyrene (cellulose- $g$-PS) was synthesized by ATRP process of styrene using cellulose- $\mathrm{Br}$ as the macroinitiator. In a typical process, the reaction mixture (styrene : $-\mathrm{Br}$ (in cellulose-Br) : CuBr : PMDETA = $500: 1: 1: 1$ (molar ratio) in toluene (1 g St in $1 \mathrm{~mL}$ solvent)) was added into an ampule, degassed by three freeze-evacuate-thaw cycles in liquid $N_{2}$, and then the ampoule was immersed into an oil bath at $90^{\circ} \mathrm{C}$. The polymerization was stopped at different times by removing the ampoule from the oil bath and cooling it in the ice/water bath. Next, the crude solution was diluted with chloroform and passed through a neutral alumina column to remove copper salt. After concentration, the cellulose-g-PS polymers were recovered by precipitating in methanol and filtration. The final product bottlebrush-like cellulose- $g$-PS, was obtained by dissolution/precipitation twice with chloroform and methanol and dried at $50^{\circ} \mathrm{C}$ under vacuum for $24 \mathrm{~h}$. 
Supporting Information

\section{Synthesis of BBCP cellulose- $g$-(PS- $b$-PTMSPMA) via ATRP}

Bottle-brushed copolymers with linear diblock copolymer PS- $b$-PTMSPMA as side chains, cellulose- $g$ (PS- $b$-PTMSPMA), were prepared by ATRP of TMSPMA using cellulose- $g$-PS as the cylindrical macroinitiator. In a typical ATRP procedure, an ampule was charged with cellulose- $g$-PS $(0.5 \mathrm{~g}), \mathrm{CuBr}$ (0.022g), PMDETA $(0.026 \mathrm{~g})$, TMSPMA $(18 \mathrm{ml})$, and anhydrous benzene $(18 \mathrm{ml})$. The reaction solution was degassed by three freeze-evacuate-thaw cycles in liquid $\mathrm{N}_{2}$ and then placed in an oil bath at $70^{\circ} \mathrm{C}$. The ampoule was taken out from the oil bath and cooled in the ice/water bath. The solution was diluted with anhydrous dichloromethane and passed through a neutral alumina column to remove the copper catalyst. The solution was then concentrated and precipitated in anhydrous petroleum ether three times to yield the pure cellulose- $g$-(PS- $b$-PTMSPMA). The final product was dried at $50^{\circ} \mathrm{C}$ under vacuum for $24 \mathrm{~h}$.

\section{Fabrication of organo-silica hybrid core/shell nanorods by intramolecular silication}

Organo-silica hybrid core/shell nanorods were prepared by gelating of outer PTMSPMA blocks in cellulose- $g$-(PS- $b$-PTMSPMA) under dilute condition. In a typical process, $0.5 \mathrm{~g}$ of cellulose- $g$-(PS- $b$ PTMSPMA) was dissolved into $50 \mathrm{~mL}$ 1,4-dioxane mixed with $28 \%$ ammonium hydroxide ( $2 \mathrm{~mL}$ ), and then the reaction system was allowed to proceed at ambient temperature for $48 \mathrm{~h}$ under constant stirring. The final organo-silica hybrid core/shell nanorods were obtained by centrifuging (10000 RPM for $10 \mathrm{~min}$ ) to remove the solvent and then re-dispersed into $20 \mathrm{~mL}$ isopropanol.

\section{Fabrication of water-soluble silica nanotubes}

Polymer templates in organo-silica hybrid core/shell nanorods were removed by hydrolysis in acidic condition. In a typical process, $0.2 \mathrm{~g}$ of organo-silica hybrid core/shell nanorods was dispersed in 10 $\mathrm{mL} \mathrm{DMF}$, and then $2 \mathrm{~mL}$ of concentrated hydrochloric acid was added into the solution. The mixture was then transferred to a $20 \mathrm{~mL}$ Teflon-lined autoclave and then heated at $200^{\circ} \mathrm{C}$ for $2 \mathrm{~h}$. The final water-soluble silica nanotubes were obtained by centrifuging (10000 RPM for 10min) to remove the solvent, washed by isopropanol, and then re-dispersed into $10 \mathrm{~mL}$ of isopropanol.

\section{Fabrication of polymer-coated (PS or PEG) metal nanorods using HSNTs as nanoreactors}

In a typical fabrication process of Au nanorods, $20 \mathrm{mg}$ of water-soluble silica nanotubes template was dispersed in $10 \mathrm{~mL}$ of DMF at room temperature, followed by adding an appropriate amount of precursor $\left(\mathrm{HAuCl}_{4} \cdot 3 \mathrm{H}_{2} \mathrm{O}, 0.25 \mathrm{~g}\right)$. The mixture was then stirred for $1 \mathrm{~h}$ to ensure the interior cavity of nanotubes was fully loaded by precursors. Then tert-butylamine-borane complex (TBAB, $0.15 \mathrm{~g}$ ) as a reducing agent was added into the reaction solution, and then the reaction was then carried out at 60 ${ }^{\circ} \mathrm{C}$ for $4 \mathrm{~h}$. Next, the irregular by-product from outer templates was removed by low-speed centrifuging 
Supporting Information

(1000 RPM for $5 \mathrm{~min}$ ), and then the final product (core/shell Au nanorod/silica nanorods) was obtained by centrifuging (10000 RPM for $10 \mathrm{~min}$ ) to remove the solvent.

The silica shell was removed by etching to obtain naked Au nanorods. Typically, $20 \mathrm{mg}$ of core/shell $\mathrm{Au} /$ silica nanorods were dispersed into $5 \mathrm{~mL}$ of DI water, to which $2 \mathrm{~mL}$ of $\mathrm{NaOH}(1 \mathrm{M})$ was added. The solution was stirred at room temperature for $12 \mathrm{~h}$. The Au nanorods were obtained by centrifuging (10000 RPM for 10min) and washed with DMF. Similarly, naked Au nanorods (10 mg) and thiolterminated PS (PS-SH, 50mg) were dispersed into $20 \mathrm{~mL}$ of toluene by ultrasonic condition for $2 \mathrm{~h}$. During ultrasonic dispersion, PS-SH as ligands can absorb onto the surface of Au nanorods, and then Au nanorods capped with PS as ligands (e.g., Au@PS NRs) can be obtained. The excess PS-SH can be removed by centrifuging (10000 rpm, 10min). In addition, when polymeric ligands were changed from PS-SH to mPEG-SH, the dichloromethane was used as the solvent, the other conditions were the same. Au nanorods capped with PEG as ligands (e.g., Au@PEG NRs) can be obtained.

In a typical fabrication process of $\mathrm{Ag}$ nanorods, $20 \mathrm{mg}$ of water-soluble silica nanotubes template was dispersed in $10 \mathrm{~mL}$ of DMF at room temperature, followed by adding an appropriate amount of precursor (silver nitrate $\left.\left(\mathrm{AgNO}_{3}\right), 0.12 \mathrm{~g}\right)$. The mixture was then stirred for $1 \mathrm{~h}$ to ensure the interior cavity of nanotubes was fully loaded by precursors. Then $L$-ascorbic acid $(0.18 \mathrm{~g})$ as a reducing agent was added into the reaction solution, and then the reaction was then carried out at $100{ }^{\circ} \mathrm{C}$ for $4 \mathrm{~h}$. Next, an irregular by-product from outer templates was removed by low-speed centrifuging (1000 RPM for $5 \mathrm{~min}$ ), and then the final product (core/shell $\mathrm{Ag} @ \mathrm{SiO}_{2} \mathrm{NRs}$ ) was obtained by centrifuging (10000 RPM for 10min) to remove the solvent.

In a typical fabrication process of Pt nanorods, $20 \mathrm{mg}$ of water-soluble silica nanotubes template was dispersed in $10 \mathrm{~mL}$ of DMF at room temperature, followed by adding an appropriate amount of precursor $\left(\mathrm{H}_{2} \mathrm{PtCl}_{6} .6 \mathrm{H}_{2} \mathrm{O}, 0.15 \mathrm{~g}\right)$. The mixture was then stirred for $1 \mathrm{~h}$ to ensure the interior cavity of nanotubes was fully loaded by precursors. Then ethylene glycol $(E G)(1 \mathrm{~mL})$ as a reducing agent was added into the reaction solution, and then the reaction was then carried out at $150{ }^{\circ} \mathrm{C}$ for $4 \mathrm{~h}$. An irregular by-product from outer templates was removed by low-speed centrifuging (1000 RPM for $5 \mathrm{~min}$ ), and then the final product (core/shell Pt@SiO 2 NRs) was obtained by centrifuging (10000 RPM for $10 \mathrm{~min}$ ) to remove the solvent.

After removing the silica shells, $\mathrm{Ag}$ and $\mathrm{Pt}$ nanorods were capped with $\mathrm{PS}-\mathrm{NH}_{2}$ at $150^{\circ} \mathrm{C}$, and uniform Ag and Pt nanorods capped with PS (Ag@PS and Pt@PS NRs) can be fabricated. 
Supporting Information

\section{Characterizations}

Molecular weights of polymers were characterized by size exclusion chromatography (SEC, Waters) equipped with a Waters 1515 HPLC pump and a refractive index detector (RID-0.65A, 220 V). THF was used as the mobile phase at a flow rate of $1.0 \mathrm{ml} / \mathrm{min}$ at $35^{\circ} \mathrm{C}$. Three Styragel $\mathrm{HR} 45 \mu \mathrm{m} 7.8 \times 300 \mathrm{~mm}$ (THF) columns were calibrated with ten monodisperse PS standard samples with molecular weights ranging from 500 to $2.4 \times 10^{6} \mathrm{~g} / \mathrm{mol}$. All ${ }^{1} \mathrm{H}$ NMR spectra were acquired by a Bruker $400 \mathrm{MHz}$ spectrometer, and $\mathrm{CDCl}_{3}$ was used as the solvent for all measurements. The morphologies of organosilica hybrid core/shell nanorods, corresponding nanotubes and metal nanorods were characterized by transmission electron microscopy (TEM) (JEOL TEM 100CX; operated at 100kv). Energy-dispersive x-ray spectroscopy (EDS) analysis of organo-silica hybrid core/shell nanorods and metal nanorods was carried out with scanning electron microscopy (SEM, LEO 1530, Zeiss). Crystalline structures of metal nanorods were characterized by X-ray diffraction (XRD, X'Pert PRO, Netherlands). UV-vis absorption spectra of metal nanorods were obtained using a Shimadzu UV-2600 UV-vis spectrophotometer. Weight fractions of organic composition in nanomaterials were measured by thermogravimetric analysis (TGA; TA Instrument TGA Q 50). The morphologies of cylindrical BBCPs were characterized by atomic force microscope (AFM; Bruker Dimension Icon; operated in the tapping mode at $0.5 \mathrm{~Hz}$ scanning rate), and the AFM samples were prepared by spin-coating the isopropanol solution $(1 \mathrm{mg} / \mathrm{mL})$ of BBCPs onto Si substrate at 2000 rpm for $1 \mathrm{~min}$ (Headway PWM32 spin coater). 


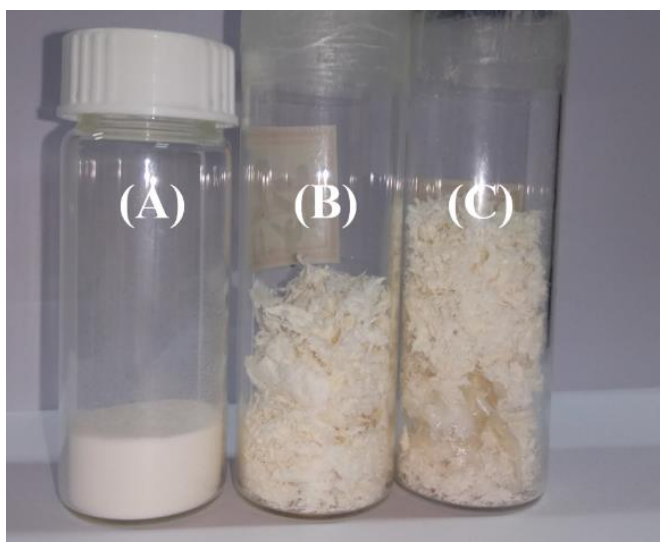

Figure S1. Comparison of natural cellulose and cellulose-Br. (A) Natural cellulose; (B) Cellulose-Br after the first esterification process; $(C)$ Cellulose-Br after the two-step esterification.

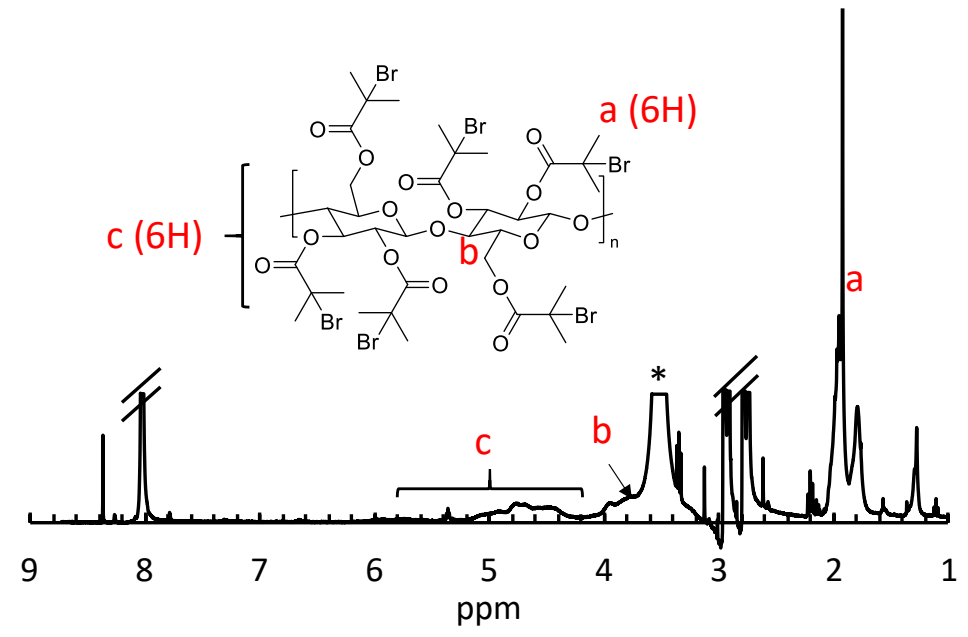

Figure S2. ${ }^{1} \mathrm{H}$ NMR spectrum of cellulose-Br (i.e., Sample-1 in Table 1; solvent: DMF- $d_{7}$ ), //: DMF; * $\mathrm{H}_{2} \mathrm{O}$; the functionalization efficiency was $83 \%$, corresponding to $5-\mathrm{Br}$ initiators per cellobiose. 


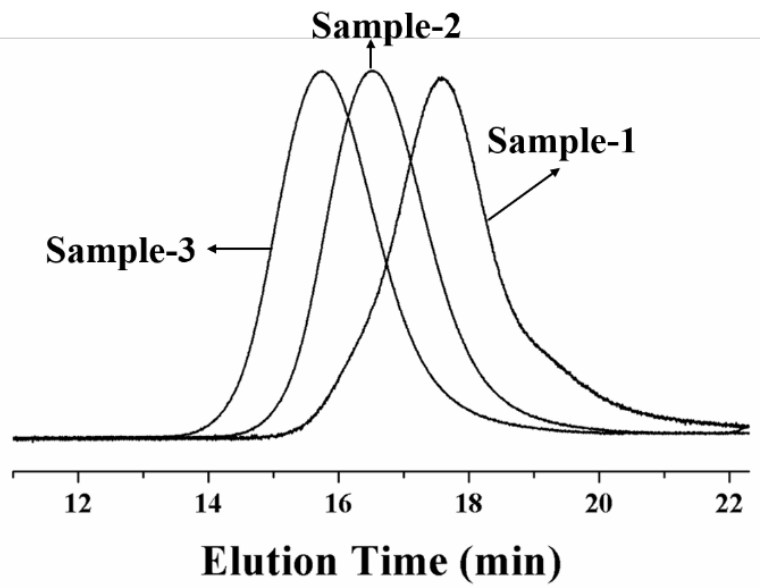

Figure S3. SEC traces of purified cellulose-Br macroinitiators with different molecular weights.

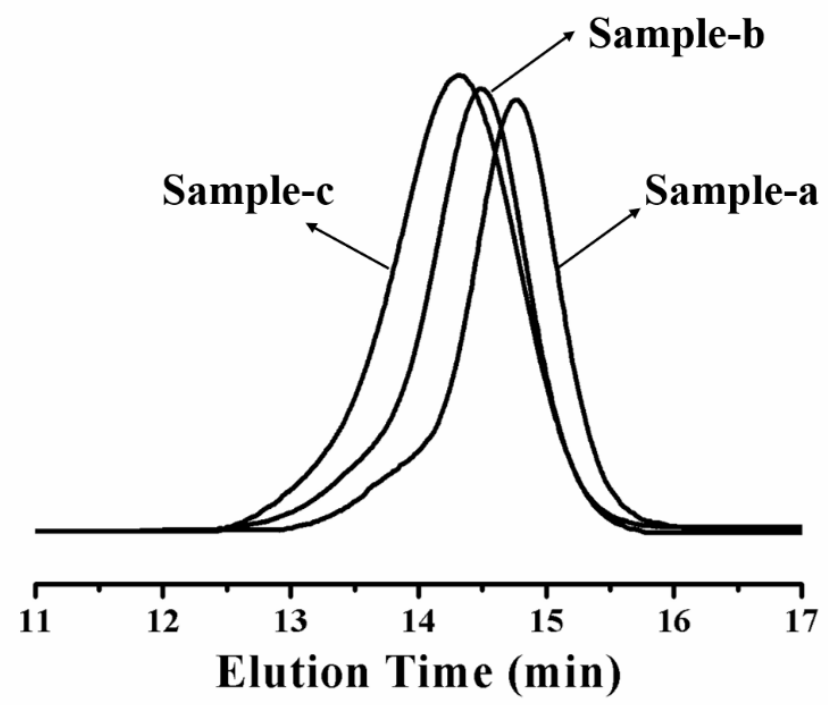

Figure S4. SEC traces of bottlebrush-like cellulose-g-PS with different molecular weights. 


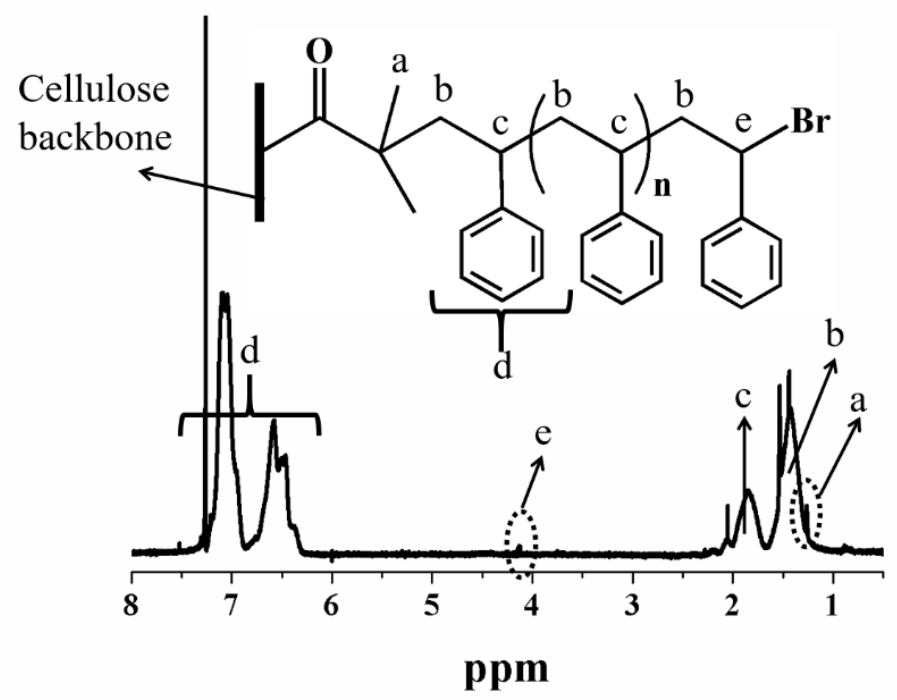

Figure S5. ${ }^{1} \mathrm{H}$ NMR spectrum of bottlebrush-like cellulose-g-PS (i.e., Sample-b in Table 1; solvent: $\left.\mathrm{CDCl}_{3}\right)$.

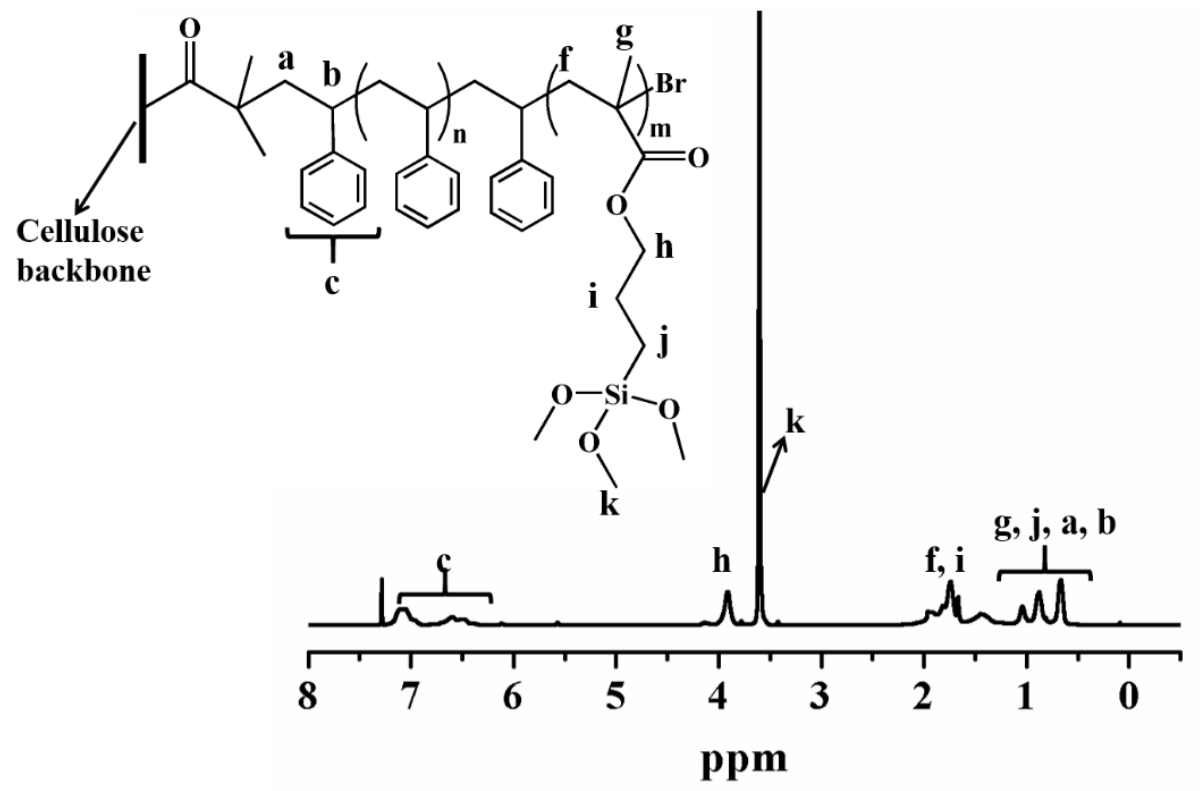

Figure S6. ${ }^{1} \mathrm{H}$ NMR spectrum of bottlebrush-like cellulose-g-(PS- $b$-PTMSPMA) (i.e., Sample-B in Table 1; solvent: $\mathrm{CDCl}_{3}$ ). 


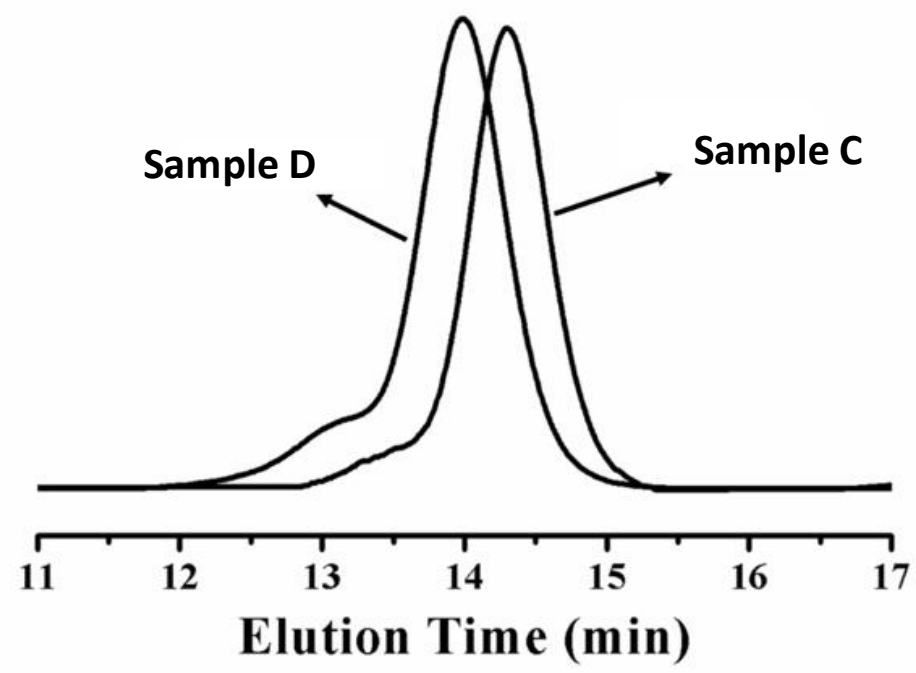

Figure S7. Typical SEC traces of bottlebrush-like copolymer cellulose-g-(PS-b-PTMSPMA) with a different chain length of PTMSPMA block (Sample $C$ and D in Table 1).
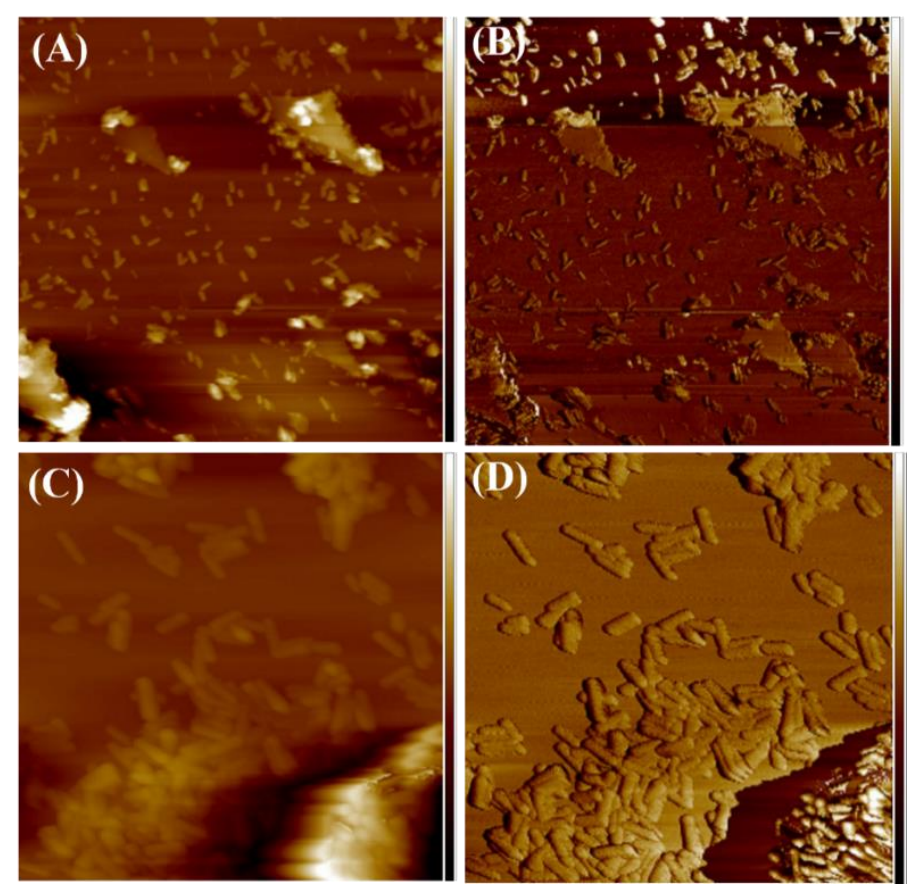

Figure S8. AFM images of organo-silica hybrid core/shell nanorods fabricated by bottlebrush-like copolymer cellulose-g-(PS- $b$-PTMSPMA) (sample-A in Table S3) as unimolecular template at different magnifications. (A) AFM height and (B) phase images, image size $=5.0 \times 5.0 \mu \mathrm{m}^{2}, \mathrm{Z}$ range $=110.6 \mathrm{~nm}$ for

(A) and $25.4^{\circ}$ for (B); (C) AFM height and (D) phase images, image size $=2.0 \times 2.0 \mu \mathrm{m}^{2}, \mathrm{Z}$ range $=$ $265.9 \mathrm{~nm}$ for (C) and $13.3^{\circ}$ for (D). 


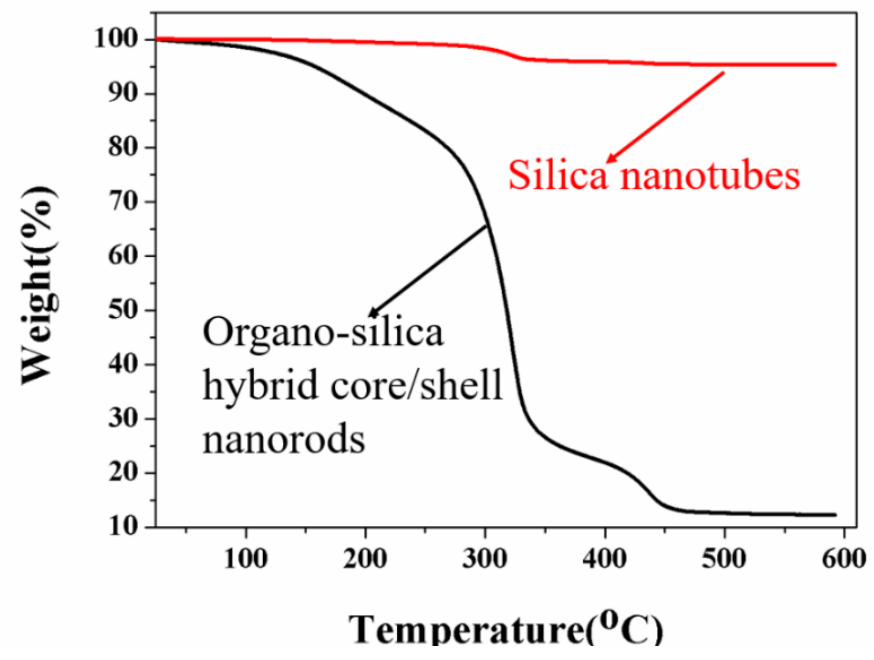

Figure S9. TGA curves of organo-silica hybrid core/shell nanorods and corresponding silica nanotubes in the air (heat rate: $10^{\circ} \mathrm{C} / \mathrm{min}$ ).
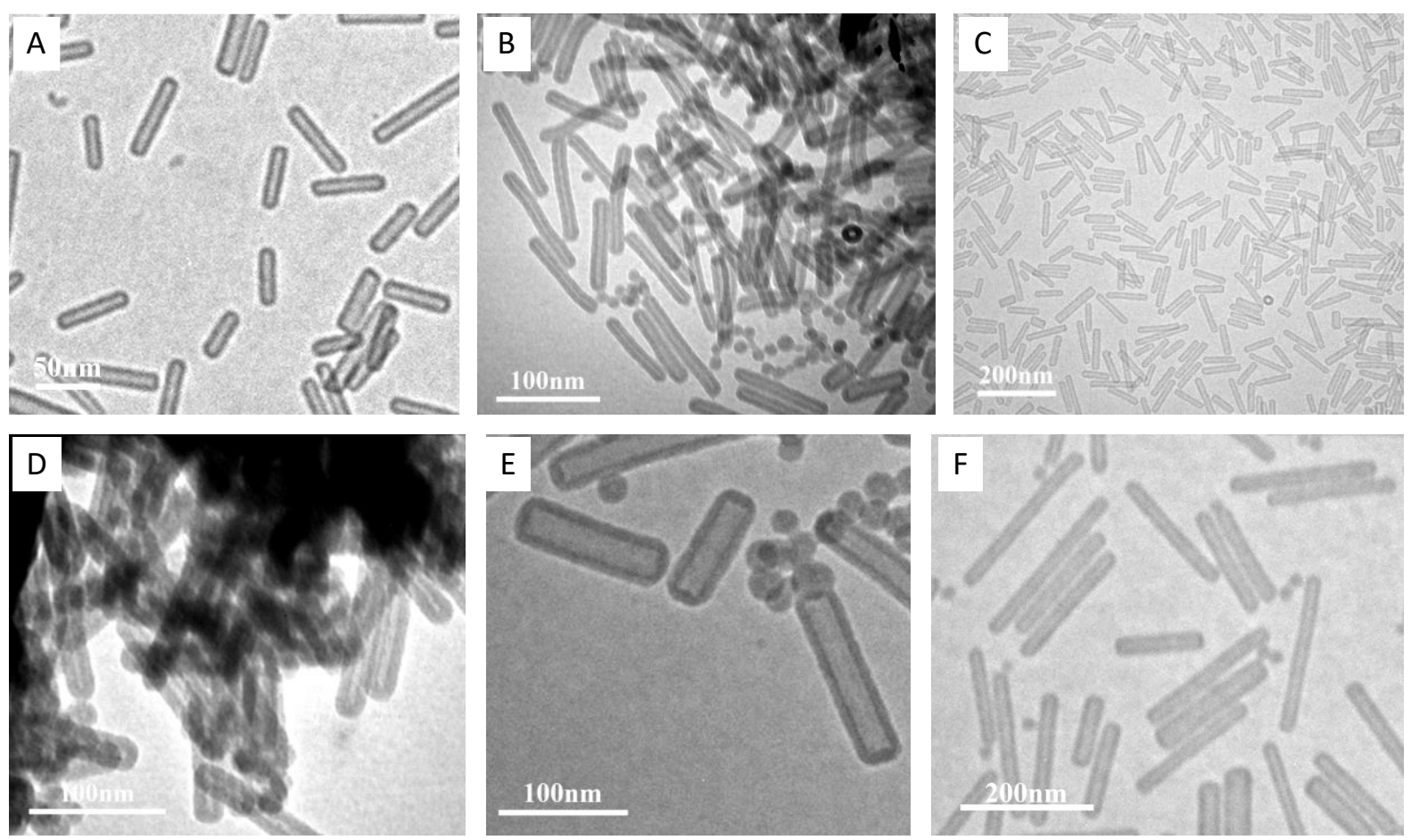

Figure S10. TEM images A-F corresponding to HSNTs fabricated from BBCPs A-F in Table 1. 


\section{Supporting Information}

Table S1. Size of all HSCNs from all six bottlebrush-like block copolymers

\begin{tabular}{|c|c|c|c|c|c|c|}
\hline \multirow{2}{*}{ Cellulose-g-(PS-b-PTMSPMA) } & \multicolumn{3}{|c|}{$\mathrm{DP}^{\mathrm{a}}$} & \multicolumn{3}{|c|}{ Size $(n m)^{b}$} \\
\hline & Cellulose & PS & PTMSTMA & $\mathrm{L}$ & $\mathrm{D}$ & $\mathrm{h}$ \\
\hline A & 17 & 47 & 25 & $59 \pm 5$ & $5.8 \pm 0.8$ & $4.6 \pm 0.5$ \\
\hline$B$ & \multirow{4}{*}{40} & 50 & 26 & $94 \pm 13$ & $6.5 \pm 0.7$ & $5.2 \pm 0.4$ \\
\hline C & & \multirow{2}{*}{120} & 27 & $114 \pm 10$ & $10.5 \pm 2.1$ & $5.1 \pm 0.4$ \\
\hline $\mathrm{D}$ & & & 71 & $106 \pm 11$ & $10.5 \pm 0.9$ & $11.2 \pm 0.9$ \\
\hline$E$ & & 268 & 27 & $116 \pm 16$ & $21.8 \pm 0.6$ & $7.2 \pm 1.0$ \\
\hline $\mathrm{F}$ & 63 & 113 & 26 & $196 \pm 18$ & $11.8 \pm 2.4$ & $7.3 \pm 1.1$ \\
\hline
\end{tabular}

a DP of polymer blocks calculated based on SEC (for cellulose) and ${ }^{1} \mathrm{H}$ NMR (for PS and PTMSPMA); ${ }^{\text {b }}$ Sizes were measured based on 5-20 HSNTs.

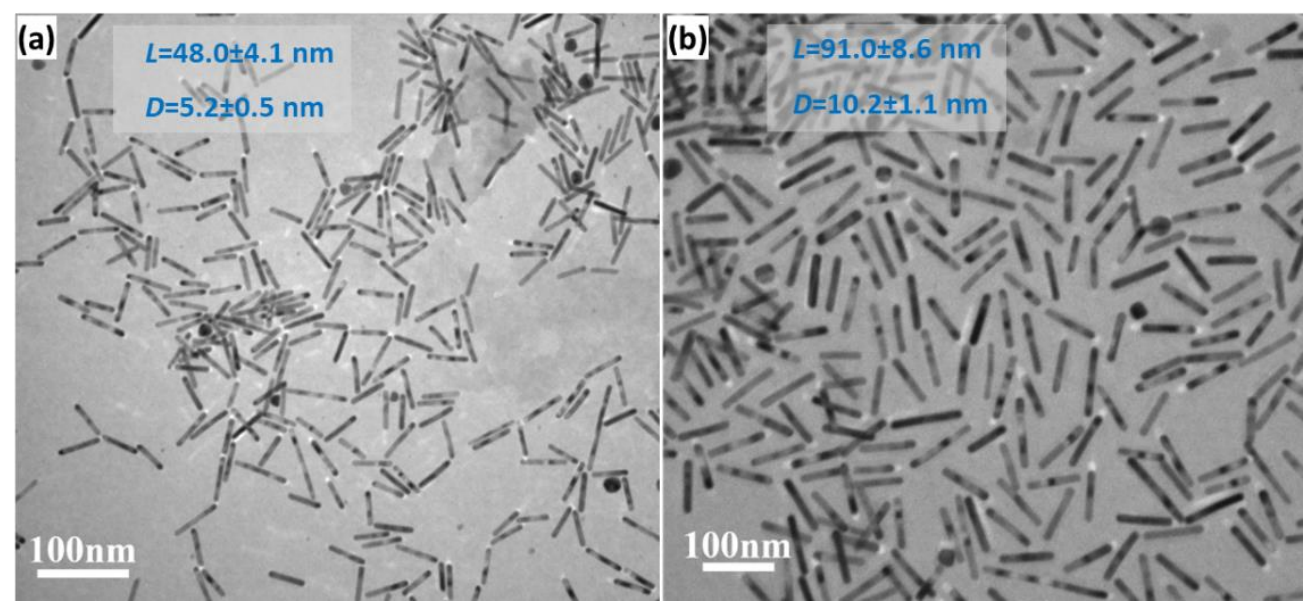

Figure S11. TEM images of Au@PS NRs fabricated using HSNT nanoreactors made from (a) BBCP A and (b) BBCP C in Table 1.

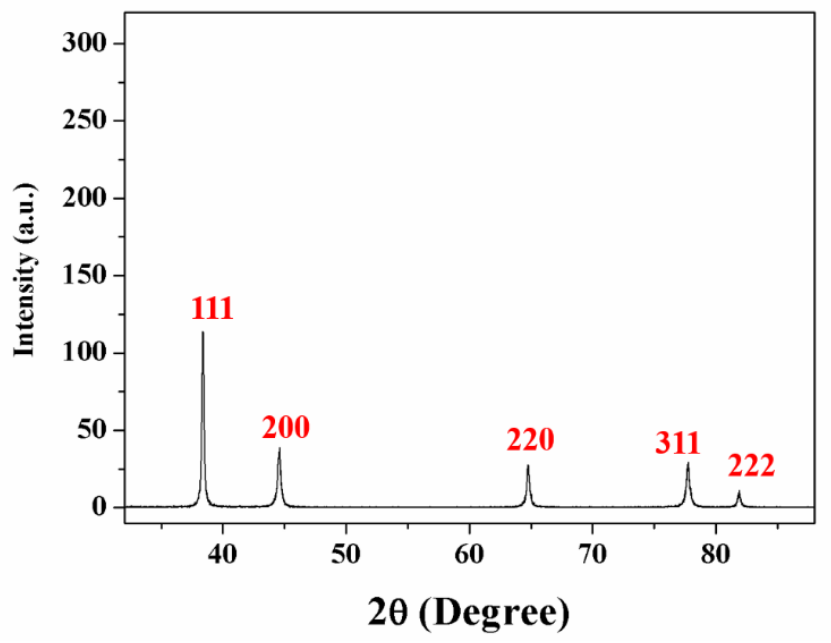

Figure S12. XRD pattern of Au@PS nanorods (JCPDS 04-0784). 
Supporting Information
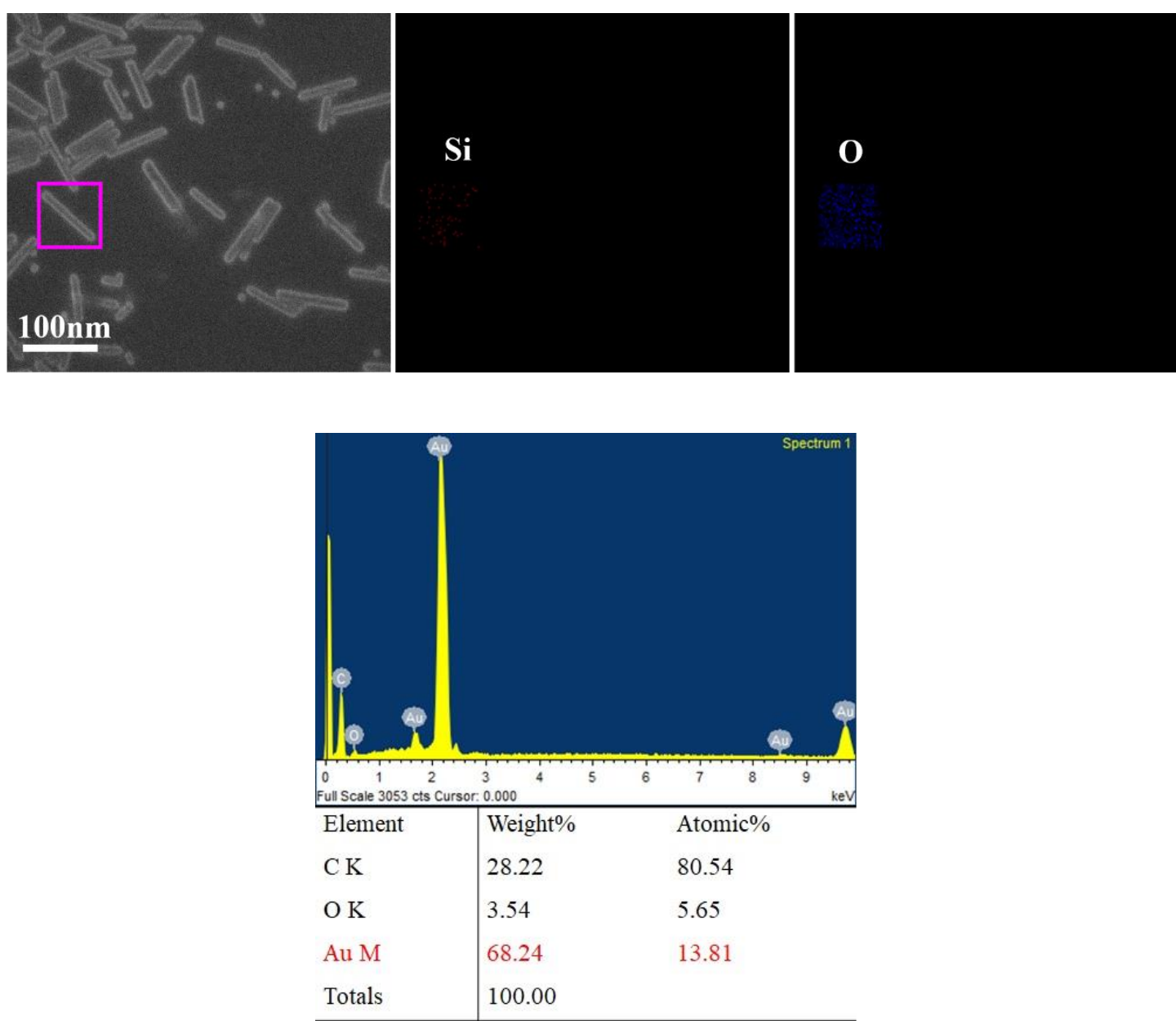

Figure S13. EDS spectrum of Au@PS nanorods.

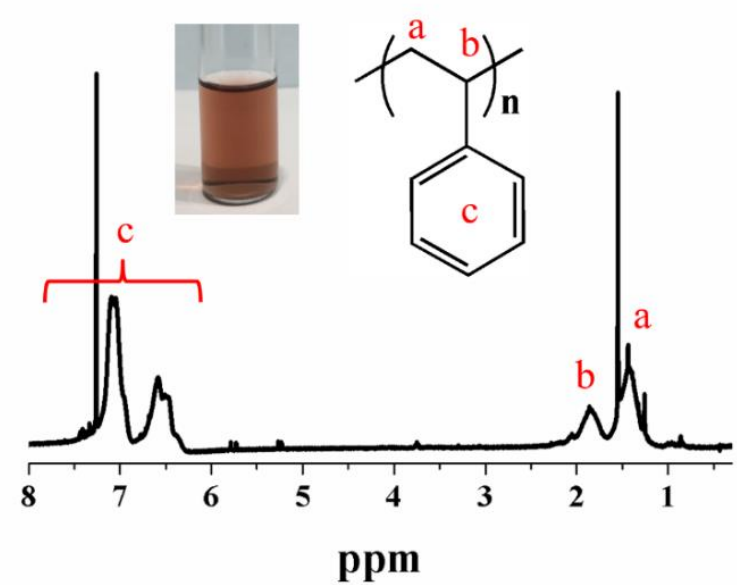

Figure S14. ${ }^{1} \mathrm{H}$ NMR spectrum of Au nanorods coated with PS as ligands (Au@PS NRs, solvent: $\mathrm{CDCl}_{3}$ ). Inset: digital image of $\mathrm{CDCl}_{3}$ solution of Au@PS NRs. ${ }^{2}$ 

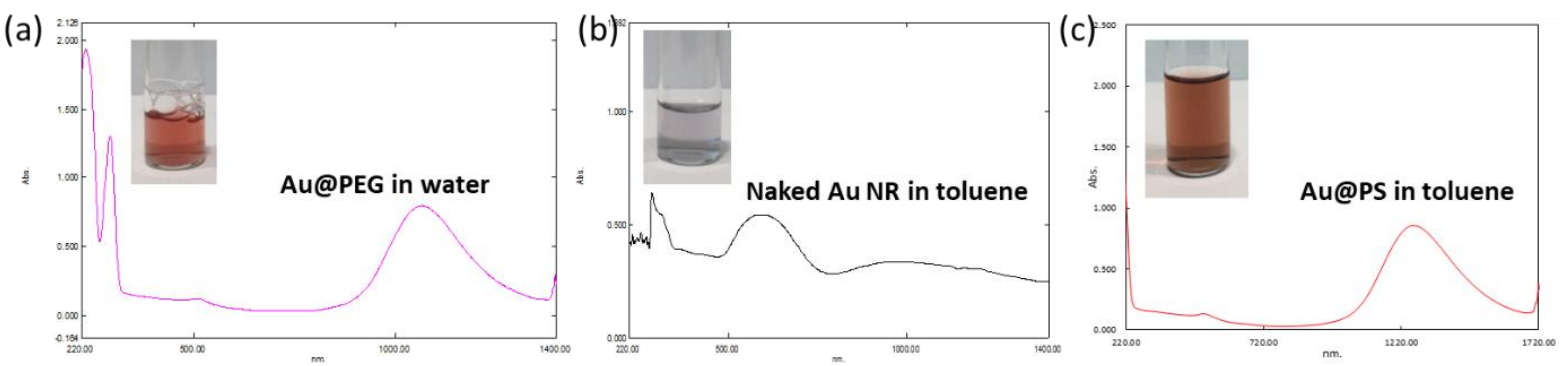

Figure S15. UV-Vis-NIR absorption spectra of (a) Au@PEG in water, (b) naked Au NRs in toluene and

(c) Au@PS NRs in toluene; inset in (a): Au@PEG in water, (b) naked Au NRs in toluene, and (c) $\mathrm{Au} @ \mathrm{NRs}$ in $\left.\mathrm{CDCl}_{3}\right)$.

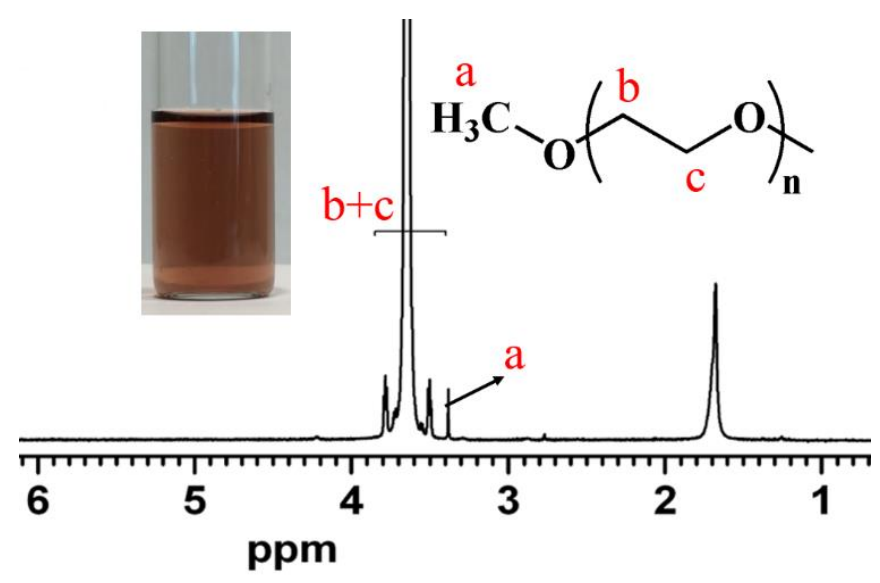

Figure S16. ${ }^{1} \mathrm{H}$ NMR spectrum of Au@PEG NRs (solvent: $\mathrm{CDCl}_{3}$ ). Inset: digital image of $\mathrm{CDCl}_{3}$ solution of Au@PEG. 
Supporting Information
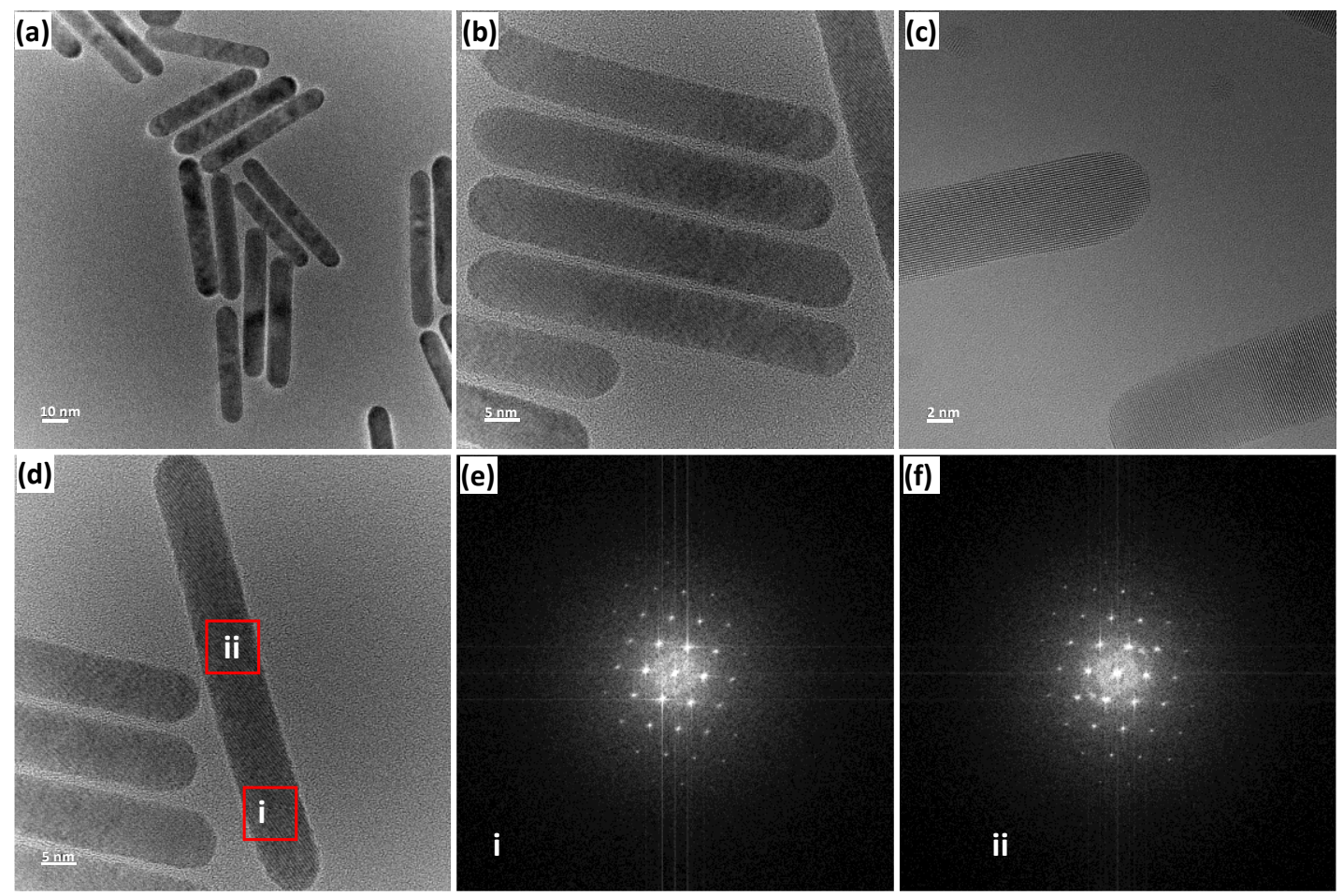

Figure S17. Cs-Corrected High-Resolution TEM Au NRs fabricated using HSNT nanoreactors from BBCP C in Table 1. (a-d TEM images, and e-f Electron diffraction patterns for segments (i) and (ii) in (d), respectively.

\section{References}

(1) Xu, Z.; Hou, Y.; Sun, S. Magnetic core/shell fe3o4/au and fe304/au/ag nanoparticles with tunable plasmonic properties. J. Am. Chem. Soc. 2007, 129, 8698-8699.

(2) Vigderman, L.; Zubarev, E. R. High-yield synthesis of gold nanorods with longitudinal spr peak greater than $1200 \mathrm{~nm}$ using hydroquinone as a reducing agent. Chem. Mater. 2013, 25, 1450-1457.

(3) Huang, X.; Neretina, S.; El-Sayed, M. A. Gold nanorods: From synthesis and properties to biological and biomedical applications. Adv. Mater. 2009, 21, 4880-4910. 